\title{
МОДЕЛЬ ОЦЕНКИ ЭФФЕКТИВНОСТИ ПРИМЕНЕНИЯ КРИТЕРИЕВ САМОСТОЯТЕЛЬНОЙ ОЦЕНКИ НАЛОГОВЫХ РИСКОВ В ТЕНЕВОМ СЕКТОРЕ
}

\begin{abstract}
Аннотация: В настоящей статье предметом исследования является теневая предпринимательская деятельность, осуществляемая организациями с высокими налоговыми рисками. Акцентируется внимание на причинах ухода налогоплательщиков в теневой сектор экономики, стимулом для которого выступает ожидаемый доход, получаемый в этой сфрере. В общем виде применение Критериев самостоятельной оценки налоговых рисков, разработанных ФНС России, направлено на противодействие теневой экономической деятельности и выявление схем уклонения от уплаты налогов. Для оценки эффрективности применения Критериев введено понятие «зона риска», от деятельности предприятий в которой для оценки ожидаемого дохода предложена экономико-математическая модель. Применение предлагаемой модели позволяет определить основные направления сокращения доходности предприятий, осуществляющих деятельность в зоне риска. В статье проанализированы основные причины ухода налогоплательщиков в теневой сектор, главными из которых выступают высокая налоговая нагрузка и низкая эфрфективность налоговых органов. Предложена модель количественной оценки суммарной налоговой нагрузки по типам производств, обоснован и предложен комплекс мероприятий по выбору оптимальной стратегии взыскания недоимки в бюджет налоговыми органами.

Ключевые слова: теневая экономика, налоговые риски, оценка теневых доходов, модель оценки, налоговая нагрузка, налоговая задолженность, распределение валовой выручки, единая база налогообложения, добавленная стоимость, стратегия взыскания недоимки.
\end{abstract}

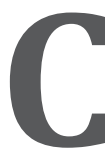
о времен возникновения общиннораспределительных отношений и последующего оформления органов государственного регулирования теневая экономика сосуществует наряду с легальной, выступая в качестве специфической подсистемы социально-экономических отношений. В современном обществе она присутствует в различных формах и масштабах во всех странах мира и сферах экономической деятельности - производстве, обмене, распределении и потреблении.

Отметим сразу, что термин «теневая экономика» не определена законодательно, вследствие чего каждый исследователь вкладывает в него свое понятие, что вызывает разброс в толковании и оценке ее доли в ВВП. Приведем некоторые из них.
Так, Ю.В. Латов считает, что «теневой экономикой называют все виды экономической деятельности, которые не отражены в официальной статистике» ${ }^{1}$. При этом особое внимание им обращается «...на те из них, которые идут вразрез с правовыми нормами и связаны с нарушениями закона. Теневая экономика является реакцией на регулирование хозяйственной жизни общества какими-либо институтами (прежде всего государством) которые вырабатывают некоторые «правила игры», полезные для общества в целом, но наносящие ущерб многим конкретным лицам»².

\footnotetext{
1 Латов Ю. В. Теневая экономика: экономический и социальный аспекты: Пробл. — темат. сб. М., 1992. — С. 92-102. 2 Там же.
} 
В. Радаев предлагает четко разграничить теневую и криминальную экономику. По его мнению, теневая экономика включает экономическую деятельность, которая осознанно скрывается от учета, не регистрируется в официальной отчетности и в специальных договорах. Он отмечает: «Очень важно отделять теневую экономику от чистого криминала. Основная часть первой не связана с явным криминалом, ибо эта деятельность по своему содержанию и целям не является нарушением закона, но связана с систематическими выходами за его пределы, чаще всего с целью неуплаты налогов или частичной уплаты налогов, еще каких-то обстоятельств» ${ }^{3}$.

Ю. Н. Попов и М. Е. Тарасов, анализируя формы теневой экономики и различные подходы к ее классификации, в конечном итоге, также разделяют теневую экономику на криминальную и нелегальную4.

По методике оценки Федеральной службы государственной статистики, в 2011 году объемы теневой экономики в России составили 16 \% от ВВП, в которой занято примерно 13 млн. человек с доходами от незадекларированной деятельности около 7 трлн. рублей 5 .

Некоторые эксперты оценивают объемы теневой экономики России на уровне 50\% ВВП и выше. Так, согласно опубликованным Всемирным Банком данным по 151 стране, в России доля скрытой от официального учета экономики составила

\footnotetext{
3 Радаев В. Деформализация правил и уход от налогов в российской хозяйственной деятельности / В. Радаев // Вопр. экономики. - 2001. - №6. - С. 60-79.

4 Попов Ю.Н. Теневая экономика в системе рыночного хозяйства: учебник / Ю. Н. Попов, М. Е. Тарасов - М.: Дело, 2005. - С.50.

5 Глава Росстата: «Серая «экономика в РФ составляет $16 \%$ от ВВП». // www.rosbalt.ru/ business/2011/04/01.
}

почти 50\% ВВП 6 . При этом отмечается, что теневая деятельность получила наиболее широкое применение в таких сферах, как торговля, услуги, производство продуктов питания, сельское хозяйство, а также незаконные виды деятельности и отрасли, в которых высок уровень коррупционной составляющей.

Из вышесказанного можно сделать вывод, что объёмы теневой экономики и, соответственно, теневых доходов в нашей стране существенны, и это негативно влияет на экономическую ситуацию и экономическое развитие страны в целом, проявляясь в различных социально-экономических деформациях, главным образом в налоговых отношениях.

Деформация налоговой сферы выражается в неэффективном распределении налоговой нагрузки, что влечет сокращение бюджетных расходов и ставит под угрозу финансирование бюджетных обязательств со стороны государства. Ведение предпринимательской деятельности без учета и регистрации ведет к неуплате налогов (не без помощи коррупции), что приводит к необходимости увеличения налогообложения доходов законопослушных налогоплательщиков. Дальше по спирали: возрастание налоговой нагрузки стимулирует дальнейшее сокрытие доходов от налогообложения, усиливает неоправданную дифференциацию доходов и собственности. Наемные работники тоже постепенно переходят на нелегальную деятельность из сферы общественно-полезного труда легальных работников. В результате общий объем производства не увеличивается, а официальная его часть становится мень-

\footnotetext{
6 Всемирный банк бросил тень на Россию: За время кризиса доля теневого сектора могла только подрасти // Независимая газета 23.07.2010. — http://www.ng.ru/ economics/2010-07-23/1_vb.html
} 
ше, что приводит к снижению налоговых поступлений. Таким образом, сокрытие даже разрешенной законом предпринимательской деятельности вызывает перераспределение доходов и собственности путем деформации налоговой политики и налоговых отношений.

Рассматривая деятельность хозяйствующих субъектов в Российской Федерации, отметим экономически неоправданно высокий уровень дебиторской и кредиторской задолженностей предприятий, что отвлекает из оборота денежные средства. Кроме того, это значительно усложняет оценку реального финансового состояния предприятия соответствующими государственными органами, а значит, является дополнительным стимулом ухода в тень.

Не вдаваясь в подробности определений, отметим, что теневая экономика не контролируется государством, хотя деятельность официально зарегистрирована (именно это и будем рассматривать в статье), но с него не уплачиваются налоги вообще или уплачиваются неполностью.

В соответствии с вышеприведенными классификациями, теневую экономику, как часть экономической сферы государства, условно можно разделить на:

- легальную, которая пользуется несовершенством действующего законодательства. Формально такой вид экономики нельзя считать теневым. Однако влияние которое она оказывает на экономику, по сути такое же, как и теневая экономика, так как государство недополучает средства;

- полулегальную, в доходах которой не учитываются объемы реализации неучтенной продукции, выполненных работ, оказанных услуг и полученной прибыли;
- неофициальную, к которой относим широко распространенные формы незарегистрированного предпринимательства («челночная» торговля, частное строительство, репетиторство, посредническая деятельность на рынке недвижимости, купля-продажа автотранспортных средств, работа в домашних условиях и др.);

- криминальную, ориентированную на ведение запрещенной законом деятельности и противоречащую не только налоговому, но и уголовному законодательству.

Отметим, что оценка влияния теневого сектора на экономику не однозначно. Как отмечали выше, расширение теневого капитала сужает базу налогообложения, увеличивая налоговую нагрузку на легально функционирующие предприятия, что заставляет и их также уходить из легального сектора экономики. И как результат уменьшение финансовых ресурсов государства и невозможность выполнения им своих функций в полном объеме. С другой стороны, теневая экономика - это достаточно большой и функционирующий по реальным рыночным законам (товарденьги-товар) вид деятельности, в которой производятся товары и оказываются услуги, стимулируются процессы первоначального накопления капитала, служит дополнительным, а зачастую и единственным источником доходов для населения, особенно в трудоизбыточных регионах.

Таким образом, деятельность в теневом секторе с одной стороны снимает ряд социальных проблем, а с другой - способствует дальнейшей социальной дифференциации общества, что представляет собой угрозу не только экономической, но и национальной безопасности страны и не способствует развитию официальной части экономики. 
В этой связи, наличие и функционирование теневой экономики можно рассматривать как неэффективную деятельность государственных институтов в лице уполномоченных контролирующих структур по пресечению роста и сокращению теневого сектора экономики. То есть, можно сказать, что государство в лице чиновников сознательно и не безвозмездно соглашается с определенным уровнем теневой экономики.

Чтобы найти пути пресечения коррупции и заставить этот сектор работать в интересах государства, рассмотрим причины ухода в тень. На начальном этапе перехода России к рыночной экономике основной причиной ухода в тень было незаконное происхождение и использование капитала. В этот период наблюдалась высокая криминализация теневой экономики, размеры которой постепенно ограничивались ввиду больших издержек и риска при функционировании в нем.

Большие объемы теневого сектора тогда можно объяснить ростом долей первых трех видов теневой экономики: легального, полулегального и неофициального. Увеличение их доли в теневом секторе предопределялось чисто экономическими причинами и недостатками налоговой системы России. Учитывая, что эти виды теневой экономики функционируют в основном в сфере легального производства, то конфликтуют они только с законодательством в экономической сфере, то есть в основном с налоговым законодательством. Предлагаемые меры, как, например, единовременное списание налоговой задолженности ${ }^{7}$, не способны в такой ситуации

\footnotetext{
7 Так, за 2011 год в рамках ст. 59 НК РФ была списана налоговая задолженность в сумме 155 954,1 млн. руб., в 2012 г. - 185 903,9 млн. руб., в 2013 г. — 147 875,3 млн. руб. В соответствии с Приказом ФНС России от
}

привлечь теневой капитал в легальный оборот, так как они не решают глобальных причин ухода капитала в тень - коррупционная поддержка и высокие ожидаемые доходы от теневой деятельности.

Таким образом, можно утверждать о наличии в экономике сформировавшейся структуры, способной реально «конкурировать» с государством в сфере налогообложения. Более того, как показывает практика, функционирование «в тени», с экономической точки зрения, оказывается выгоднее для хозяйствующих субъектов. Именно поэтому разработка мероприятий по противодействию уклонения от налогообложения и совершенствование налогового администрирования объявлены приоритетами в области налоговой политики на 2014 год и плановый период 2015-2016 годов ${ }^{8}$.

В целях совершенствования практики отбора налогоплательщиков для проведения выездных налоговых проверок в мае 2007 года ФНС России издала Приказ от 30.05.2007 № MМ-3-06/333@ ${ }^{9}$, в котором были утверждены Коцепция системы планирования выездных налоговых проверок и Общедоступные критерии самостоятельной оценки рисков для налогоплательщи-

19.08.2010 № ЯК-7-8/392@ списана в 2011 г. — 77 747,6 млн. руб., в 2012 г. — 29 287,4 млн. руб., в 2013 г. 16 168,5 млн. рублей. (Источник: Официальный сайт ФНС России www. nalog.ru Отчет ф. №4-НМ)

8 Основные направления налоговой политики Российской Федерации на 2014 год и на плановый период 2015 и 2016 годов (Одобрено Правительством Российской Федерации 30 мая 2013 года). http://www. consultant.ru/document/cons_doc_LAW_147172/

9 См.: Приказ ФНС России от 30 мая 2007 г. № ММ3-06/333@ Об утверждении концепции планирования выездных налоговых проверок (в ред. Приказов ФНС России от 14.10.2008 №ММ-3-2/467@, от 22.09.2010 №MMB-7-2/461@, от 08.04.2011 № MMB-7-2/258@, от 10.05.2012 № MMB-7-2/297@). http://base.consultant.ru/cons/cgi/online. cgi?req $=$ doc $;$ base $=$ LAW; $=129610$ 
ков. Применение этих критериев позволяет в определенной степени повысить налоговую грамотность и дисциплинированность налогоплательщиков, а с другой-выявляет наиболее вероятные «зоны риска» и, тем самым, определить комплекс необходимых мероприятий налогового контроля. Периодически эти критерии дополняются новыми в результате обобщения практики контрольной работы на уровне ФНС России.

В широком смысле применение критериев направлено на противодействие теневой экономической деятельности налогоплательщиков и помогает выявить незаконные схемы уклонения от уплаты налогов. Все это хорошо и направлено на большую прозрачность во взаимоотношениях налоговых органов с бизнес-сообществом. Но на повестку дня встает вопрос: а какова эффективность применения этих критериев для налоговых органов? Какими показателями оценивается эффективность? Ответов пока нет.

Итак, для моделирования процесса оценки эффективности применения вышеуказанных критериев введем понятие «зоны риска». Под зоной риска подразумевается достижение значения и/или наступление события, утвержденного и/или описанного в общедоступных критериях.

Отметим сразу, что понятие «теневая экономика» рассматривается как явление, процесс, а «зона риска»-его оценочный показатель. Используемые нами понятия применимы исключительно в правоотношениях налоговых органов и налогоплательщиков. То есть, например, налогоплательщик официально зарегистрирован и состоит на учете, занимается деятельностью, не запрещенной законом, но укрывает от налогов часть результатов хозяй- ственной деятельности, имеет налоговую задолженность и т.д. В этом случае его деятельность не оценивается как теневая, кроме как налоговыми органами, вследствие попадания в зону риска.

Другими словами, в нашей модели налогоплательщики, попавшие в зону риска и не представившие пояснения на уведомление налогового органа (9-й критерий) априори отвлекают часть денежных средств в теневой сектор и применяют серые схемы уклонения от уплаты налогов, которые не обнаруживаются или зачастую «не замечают» коррумпированные должностные лица налоговых органов.

Стимулом к ведению хозяйственной деятельности в зоне риска является ожидаемый доход, который формально можно определить следующим образом:

$$
R=(1-p) S+p(S-D)=S-p D ，
$$

где: $R$ - ожидаемый доход от функционирования в зоне риска;

$p$ - вероятность обнаружения теневых схем налоговыми органами;

$S$ - величина валового дохода от функционирования в зоне риска;

$D$ - потери в денежном виде в результате обнаружения нарушений.

Чем выше ожидаемый доход от теневой деятельности, тем выше стимулы к функционированию в зоне риска. Таким образом, можно сделать вывод, что рост доходности в зоне риска способствует росту объема теневого сектора. В данном случае доходность в зоне риска определяется как разность между полными налоговыми затратами при функционировании в легальной экономике и полными затратами на функционирование в теневой экономике. В свою очередь затраты в легальном секторе определяются следующими величинами: 
- совокупные налоговые затраты (налоговая нагрузка) на основную деятельность в соответствии с действующим налоговым законодательством. Ее величина определяется нормативными документами по налогообло-жению;

- административные затраты, то есть затраты, связанные с функционированием системы налогового менеджмента на предприятии. К ним можно отнести затраты на проведение внешнего аудита; затраты связанные с повышением профессионального уровня сотрудников; информационным обеспечением сотрудников, ответственных за налоговое планирование; затраты, связанные с внедрением системы налогового менеджмента на предприятии и т.п.;

- непредвиденные затраты - это затраты возникающие в результате непреднамеренных ошибок в налоговом учете, например ввиду различного толкования налоговых норм на предприятии и налоговыми органами, вероятность возникновения которых в условиях сложности, запутанности и частых изменений налогового законодательства достаточно высока. К этим затратам, кроме сумм доначисленных обязательств также следует отнести суммы пени и штрафов, а также возможные затраты на досудебные и судебные разбирательства. Вообще говоря, непрямые затраты могут рассматриваться как некоторая случайная величина.

В структуре затрат на деятельность в зоне риска будем выделять определенный процент от скрываемого дохода (или иного вида деятельности), который в легальных условиях подлежит налогообложению, а в условиях функционирования в зоне риска является премией (коррупционные выплаты) посредникам или чиновникам. Таким образом, детерминированные затраты на функционирование в зоне риска можно условно представить как единый налог на определенный вид деятельности по сокрытию определенной операции.

Тогда доход от функционирования в зоне риска можно оценить следующей формулой:

$$
S=Y \cdot T_{T}+Z_{N M}+p_{N P} Z_{N P}-Y \cdot R_{p},
$$

где: $Y$ - совокупная база налогообложения предприятия;

$T_{T}$ - совокупная налоговая нагрузка на предприятие;

$Z_{N M}$ - затраты на внедрение и функционирование системы налогового менеджмента на предприятии;

$p_{N P}-$ вероятность наступления непредвиденных затрат;

$Z_{N P}$ - сумма непредвиденных затрат, включая доначисления, пени штрафы и судебные издержки;

$R_{p}$ - ставка премии за посреднические услуги или «услуги» чиновников при функционировании в зоне риска.

Таким образом, ожидаемый доход от деятельности в зоне риска может быть оценен следующим образом:

$R=Y \cdot T_{T}+Z_{N M}+p_{N P} Z_{N P}-Y \cdot R_{p}-p D \cdot(1)$

Анализ формулы (1) позволяет сформулировать основные мероприятия, реализация которых может привести к сокращению теневого сектора и уменьшению доходности налогоплательщиков, осуществляющих деятельность в зоне риска. К ним относятся:

1. Сокращение совокупной налоговой нагрузки. Вопросы определения оптимальной налоговой нагрузки представляют собой достаточно сложный про- 
цесс, в котором должны учитываться не только экономические факторы, но и параметры социальной политики государства, эффективность бюджетных расходов и т.д.

2. Снижение затрат на внедрение и функционирование систем налогового менеджмента. Основным фактором, обуславливающим высокие затраты на эти системы является, прежде всего, нестабильное налоговое законодательство и, как следствие, высокие затраты на актуализацию этих систем.

3. Сокращение непредвиденных затрат предприятий. Ввиду того, что подобные затраты возникают как следствие сложности налоговой системы, а также как результат разночтений налогового законодательства, для стимулирования роста базы налогообложения за счет сокращения объемов теневого сектора экономики, налоговым органам имеет смысл централизовано отслеживать и периодически публиковать изменения в налоговом законодательстве и практику налоговых органов по расчету отдельных налогов и сборов. Запущенные сервисы сайта ФНС России направлены на устранение возможных разночтений налогового законодательства и будут способствовать снижению вероятности наступления непрямых затрат и затрат на актуализацию информационных систем налогового менеджмента.

4. Повышение эффективности работы налоговых органов в части выявления схем предпринимательской деятельности налогоплательщиков в зоне рисков, то есть повышение вероятности обнаружения теневых схем налоговыми органами. Основной проблемой по этому направлению является разработка и применение адекватной оцен- ки эффективности работы налоговых органов. Использование в качестве оценки этой вероятности частоты выявления на предприятиях налоговых нарушений очевидно не подходит, так как эта величина включает также вероятность наступления непредвиденных затрат, то есть:

$$
v_{N N}=p+p_{N P}
$$

где: $v_{N N}-$ частота обнаружения налоговых нарушений при проведении проверок налоговыми органами.

Так, например, для текущего состояния проблемы в России частота обнаружения нарушений при проведении выездных налоговых проверок близка к единице ${ }^{10}$, однако, это отнюдь не означает, что близка к единице вероятность обнаружения теневых схем, о чем косвенно свидетельствуют масштабы теневой экономики.

5. Повышение налоговых санкций и штрафов за нарушения налогового законодательства. В условиях, когда распределение налоговых нарушений между сознательными и непреднамеренными в основном смещено в сторону первых, то есть $\left(p>>p_{N P}\right)$, повышение налоговых санкций и штрафов действительно ведет к сокращению числа налогоплательщиков, осуществляющих деятельность в зоне рисков. Когда же наблюдается обратная ситуация, то есть $\left(p_{N P}>>p\right)$, увеличение

10 Так, согласно Докладу «Об осуществлении Федеральной налоговой службой государственного контроля (надзора) в соответствующих сферах деятельности и об эффективности такого контроля (надзора) в 2012 году»: «Количество проведенных выездных налоговых проверок составило 58,1 тыс. ... Удельный вес результативных выездных налоговых проверок сохранился почти на стопроцентном уровне (99\%). Эффективность одной выездной проверки составила 5625 тыс. рублей». 
налоговых санкций и штрафов фактически приводит к росту непредвиденных затрат в гораздо большей степени чем к росту потерь от функционирования в зоне рисков. То есть выполняется следующее неравенство:

$$
\left(p_{N P} f(D)-p D\right)_{D}^{\prime}>0
$$

где $f(D)=Z_{N P}$ - функция стохастической связи между налоговыми санкциями, штрафами и непрямыми затратами предприятия.

В этом случае оказывается, что чистый эффект от увеличения налоговых санкций и штрафов приводит к увеличению доходности от функционирования в зоне риска и способствует развитию теневого сектора.

Рассмотрим подробно вопросы оценки налоговой нагрузки на различные предприятия. Исследованию этих проблем посвящены труды ведущих российских ученых $^{11}$. Исследование тяжести налогового бремени связана с проблемой переложения налогов, была и остается актуальной на разных уровнях хозяйственной деятельности - государственном; уровне предприятий; уровне населения:

- государство на своей территории выступает как субъект управления хозяйственной деятельностью и перераспределения доходов от нее (в виде

\footnotetext{
11 См.: Например: Пансков, В. Г.Налоги и налогообложение: теория и практика: учебник для бакалавриата / В. Г. Пансков. - 2-е изд., перераб. и доп. - М.: Издательство Юрайт; ИД Юрайт, 2011. Серия: Бакалавр. С. 202-209. Кирова Е.А. Налоговая нагрузка: как ее определять? // Финансы. 2009. №4. С. 31-34. Кирина Л.С., Горохова Н.А. Сравнительная характеристика различных вариантов расчета налоговой нагрузки // Экономика. Налоги. Право. 2009. №5. С. 56-66. М.И. Литвин Налоговая нагрузка и экономические интересы предприятий // Финансы. 1998. № 5. С. 29-31. и др.
}

налогов-через бюджет) в пользу прочих направлений государственной и социальной политики;

- организации и предприятия - как субъекты предпринимательской деятельности, обеспечивающие формирование источника предпринимательского дохода и, соответственно, базы налогообложения;

- $\quad$ работники, как участники предпринимательской деятельности, обеспечивают для себя средства существования и развития.

При этом государство сравнивает тяжесть налогового бремени в собственной стране с налоговым бременем в других странах; население сравнивает доходность своего труда (оценку своих навыков, умений и интеллекта) с оценкой аналогичного труда в других компаниях или в условиях теневой экономики, или за рубежом; для предприятий же наиболее близкой альтернативой (сравнительной базой) является деятельность в зоне риска, то есть налогонеоблагаемый или частично налогооблагаемый бизнес.

Таким образом, можно утверждать, что основными причинами ухода в тень (кроме криминальной) является, во-первых, тяжелое налоговое бремя, а, во-вторых, низкая эффективность функционирования налоговых и законодательных органов.

Для доказательства этого утверждения дадим общую количественную оценку налоговой нагрузки на предприятия различного типа, выделив предприятия по трем типам производств: фондоемкое, трудоемкое и материалоемкое.

Так как налоговая система России основана на использовании налогов с различной базой, то для количественной оценки суммарной налоговой нагрузки необходимо свести их к единой интегральной оце- 
ночной базе. Для этого наиболее подходит методика Литвина М.И., в которой в качестве базы используется доля отдаваемой государству дополнительно произведенной на данном предприятии стоимости, т.е. добавленной стоимости. Под добавленной стоимостью в данном случае будем понимать все то, что выручено предприятием от продажи своей продукции (работ, услуг) за вычетом использованных в процессе деятельности материальных компонентов производства. Тогда структура добавленной стоимости может быть представлена в следующем виде:

- амортизационные отчисления;

- затраты на оплату труда (включая отчисления в социальные фонды и налоги, начисляемые на фонд оплаты труда);

- налог на добавленную стоимость;

- прибыль.

C учетом допущенных предположений тогда будет справедлива следующая модель распределения валовой выручки предприятия (табл.1):

Таблица 1

Модель распределения валовой выручки предприятия

\begin{tabular}{|c|c|c|c|c|}
\hline \multicolumn{5}{|c|}{ Валовая выручка (I) } \\
\hline Матери- & \multicolumn{3}{|c|}{ Добавленная стоимость (A) } \\
\cline { 2 - 5 } альные & Амор- & Оплата & Налог на до- & При- \\
затраты & тизация & труда & бавленную & быль \\
$(M)$ & $(D)$ & $(W)$ & стоимость (T) & $(P)$ \\
\hline
\end{tabular}

(Источник: составлена автором)

Приведем все налоги к единой базе добавленной стоимости, создаваемой на предприятии, которая в данном случае рассматривается как разность между валовой выручкой (с НДС) за вычетом материальных затрат.

Для этого введем следующие коэффициенты, характеризующие тип производства:

$$
K_{A}=\frac{A}{I}-\text { коэффициент, характери }
$$

зующий материалоемкость производства,

где: $A$ - добавленная стоимость. Чем меньше значение этого коэффициента, тем выше материалоемкость производства;

$$
\begin{aligned}
& I \text { - валовая выручка. } \\
& K_{D}=\frac{D}{A}-\text { коэффициент, характери- }
\end{aligned}
$$
зующий фондоемкость производства, где: $D$ - амортизация. Чем выше значение коэффициента, тем больше фондоемкость производства;

$$
K_{W}=\frac{W}{A}-\text { коэффициент, характери- }
$$

трудоемкость производства, где: $W$ - совокупные затраты по оплате труда. Чем больше значение этого коэффициента, тем выше трудоемкость производства.

В соответствии с действующим российским законодательством можно выделить следующие основные налоги (табл. 2).

При этом в таблице отдельной строкой выделим совокупное влияние остальных налогов и сборов со специфической базой налогообложения, например: налоги на имущество, земельный налог, транспортный налог, водный налог, сборы за пользование природными ресурсами и т.п. Так как база налогообложения для этих налогов уникальна, а совокупная доля в общей сумме налоговых отчислений достаточно стабильна, то для оценки их совокупного влияния будем использовать долю этих налогов в ВВП. За период с 2010 по 2012 годы их доля в ВВП составляла в среднем 1,82\% ${ }^{12}$. В качестве налогооблагаемой базы в этом случае будет выступать выручка от реализации.

\footnotetext{
12 См.: «Основные направления налоговой политики Российской Федерации на 2014 год и на плановый период 2015 и 2016 годов» (одобрено Правительством РФ 30.052013 г.). Данные табл. 1. http://www.consultant.ru/ document/cons_doc_LAW_147172/?frame $=4$
} 
DOI: $10.7256 / 1812-8688.2014 .4 .11890$

При цитировании этой статьи сноска на doi обязательна

Налоги и налогообложение - № 4(118) • 2014

Таблица 2

Основные налоги, уплачиваемые предприятием

\begin{tabular}{|c|l|c|l|}
\hline $\begin{array}{c}\text { № } \\
\text { п/п }\end{array}$ & \multicolumn{1}{|c|}{ Налог или сбор } & $\begin{array}{c}\text { Ставка, } \\
\text { \% }\end{array}$ & \multicolumn{1}{|c|}{ База обложения } \\
\hline 1 & Налог на добавленную стоимость (НДС) & 18 & Добавленная стоимость \\
\hline 2 & Налог на прибыль организаций & 20 & Балансовая прибыль \\
\hline 3 & Налог на доходы физических лиц (НДФЛ) & 13 & Заработная плата \\
\hline 4 & Пенсионный фонд (ПФ РФ) & 22 & Фонд оплаты труда \\
\hline 5 & $\begin{array}{l}\text { Федеральный фонд обязательного медицинского } \\
\text { страхования (ФФоМС РФ) }\end{array}$ & 5,1 & Фонд оплаты труда \\
\hline 6 & Фонд социального страхования (ФФОМС РФ) & 2,9 & Фонд оплаты труда \\
\hline 7 & Взносы на «травматизм» & 0,52 & Фонд оплаты труда \\
\hline \multicolumn{2}{|l|}{ Итого начисления на фонд оплаты труда } & 30,52 & \\
\hline 8 & Прочие налоги и сборы со специфической ставкой & 1,82 & Валовая выручка \\
\hline
\end{tabular}

(Источник: составлена автором)

* С 1 января 2014 года весь тариф взносов в Пенсионный фонд, независимо от возраста сотрудника, перечисляют на страховую часть пенсии.

** В соответствии с Федеральным законом от 22.12.2005 №179-Ф3 установлены 32 базовых тарифа в размере от $0,2 \%$ до $8,5 \%$. Для расчетов берем среднюю величину $0,52 \%$. Это значение нами определено исходя из следующих источников:

1. ЗАКЛЮЧЕНИЕ Счетной палаты РФ на Отчет об исполнении бюджета Фонда социального страхования РФ за 2011 год: «Средний страховой тариф по обязательному социальному страхованию от несчастных случаев на производстве и профессиональных заболеваний по видам экономической деятельности сложился в размере $0,52 \%$, или на 0,01 \% выше тарифа, предусмотренного расчетами и среднего размера тарифа, сложившегося в 2010 году». http://www.ach.gov.ru/userfiles/tree/katrenko12-09-12-tree_files-fl-629.pdf

2. Совет Федерации одобрил законопроект об исполнении бюджета Фонда социального страхования за 2012 год. Цитата «Среднеотраслевой тариф в итоге оказался на уровне $0,53 \%$ \%.

http://fss.ru/ru/news/89142/110200.shtml

3.Средний тариф по видам экономической деятельности в 2013 году $-0,51 \%$ к начисленной оплате труда. ИА «ГАРАНТ»: http://www.garant.ru/products/ipo/prime/doc/70422640/\#review\#ixzz2xoBNiRTn

Тогда с учетом введенных коэффициентов, обеспечивающих переход к единой базе налогообложения сумма основных налоговых платежей предприятия может быть рассчитана по следующим формулам:

1. Налог на добавленную стоимость $\left(A_{T}\right)$ :

$$
A_{T}=\frac{18 \%}{118 \%} \times A=0,1525 \times A,(2)
$$

2. Начисления на заработную плату $\left(W_{P}\right)$ :

$$
W_{P}=\frac{30,52 \%}{130,52 \%} \times K_{W} \times A=0,2338 \times K_{W} \times A,
$$

3. НДФЛ ( $\left.I_{T}\right)$ включен в данную модель, несмотря на то, что данный налог уплачивает не предприятие, а работник, поскольку альтернативой оценки труда для работника в официальной экономике является доход такого же работника в сфере теневой занятости, естественно без налогов. Совокупные начисления на заработную плату составили 13,52\%:

$I_{T}=0,1352 \times\left(1-\frac{0,3052}{1,3052}\right) \times K_{W} \times A=0,1036 \times K_{W} \times A,(4)$

4. Удельный вес прочих налогов: $R_{T}=1,82 \%$ от выручки, то есть: 


$$
R_{T}=0,0182 \times \frac{A}{K_{A},(5)}
$$

5. Налог на прибыль (20\%) $\left(P_{T}\right)$ :

$$
P_{T}=0,20 \times\left(1-\frac{0,18}{1,18}-K_{W}-K_{D}-\frac{0,0182}{K_{A}}\right) \times A,(6)
$$

Произведя вычисления в скобках формулы (6) имеем:

$$
P_{T}=0,20 \times\left(0,8475-K_{W}-K_{D}-\frac{0,0182}{K_{A}}\right) \times A,
$$

Таким образом, налоги, уплачиваемые хозяйствующим субъектом, представлены в виде доли добавленной стоимости.

Суммируя уравнения (2-6) получим суммарный налог $\left(T_{T}\right)$ :

$$
T_{T}=\left(0,322+0,1374 \times K_{W}-0,2 \times K_{D}+\frac{0,014}{K_{A}}\right) \times A,(7)
$$

Из (7) видно, что базовая налоговая нагрузка на предприятие составляет порядка $32 \%$ добавленной стоимости, что соответствует данным документа «Основные направления налоговой политики Российской Федерации на 2014 год и на плановый период 2015 и 2016 годов» (одобрено Правительством РФ 30.05.13 г.). (см. табл. 2). Изменение базовой налоговой нагрузки происходит за счет разных значений коэффициентов $K_{A}, K_{W}, K_{D}$. При этом наибольшее влияние на динамику совокупной налоговой нагрузки оказывает именно изменение коэффициента $K_{D}$ : при увеличении фондоемкости на $1 \%$ совокупные налоговые затраты уменьшаются на 0,2 \%.

Из этого вытекает вывод о том, что предприятия занятые в фондоемком производстве платят меньше налогов, что вполне экономически оправдано, ведь наибольшие затраты производятся в момент приобретения основных фондов, причем одним из источников приобретения этих фондов является прибыль после налогообложения. В рыночных условиях задача воспроизводства фондов полностью ложится на предприятие, поэтому государство в большей степени освобождает эту долю добавленной стоимости от налоговой нагрузки.

Увеличение трудоемкости производства сопровождается ростом коэффициента $K_{W}$, так из формулы (7) видно, что при увеличении трудоемкости на $1 \%$ совокупные налоговые затраты увеличиваются на $0,1374 \%$. Из этого следует, что для трудоемкого производства суммарный налог будет выше.

Увеличение материалоемкости производства ведет к уменьшению коэффициента $K_{A}$. Для оценки влияния материалоемкости на совокупную налоговую нагрузку необходимо вычислить производную $T_{T}$ по $K_{A}$ :

$$
\left(T_{T}\right)_{K_{A}}^{\prime}=-\frac{0,014}{K_{A}^{2}}
$$

Это означает, что увеличение материалоемкости производства приводит к нелинейному увеличению совокупной налоговой нагрузки, то есть, чем выше текущая материалоемкость, тем чувствительнее совокупная налоговая нагрузка к ее изменению.

Таким образом, чем выше материалоемкость производства при высоком уровне износа основных фондов, тем больше стимулов для ухода в зону риска со всеми вытекающими отсюда негативными последствиями.

Катализатором ухода в зону риска является также неисполнение налоговых обязательств в полном объеме в надежде на дальнейшее ее списание. Это приводит к росту налоговой задолженности в эко- 
номике, а от налоговых органов требуется разработка и реализация эффективных мероприятий, направленных на ее снижение. Так, по данным ФНС России наибольший удельный вес в структуре недоимки принадлежит НДС (60,3\%), а в Республике Дагестан - 72,3\% ${ }^{13}$. Это означает, что в практике администрирования в центре внимания налоговых органов должны быть предприятия - плательщики налога на добавленную стоимость.

Анализ финансового состояния предприятий-должников налоговыми органами по критериям рисков позволяет оценить их потенциальные возможности и резервы по погашению задолженностей перед бюджетом. В зависимости от полученных результатов анализа должны применяться различные механизмы и инструменты по уменьшению и ликвидации задолженностей, оптимальные для конкретного предприятия.

Общий набор механизмов и инструментов выбора стратегии взыскания недоимки налоговыми органами может быть представлен следующим комплексом мероприятий:

1. Определение множества типовых стратегий в зависимости от особенностей самого предприятия, сферы его деятельности, налогов, по которым имеется задолженность и финансового состояния предприятия.

2. Определение эффективности выделенных ранее стратегий и их результатов.

13 По данным отчета ФНС России №4-НМ (по состоянию на 01.01. 2014 г.) общая сумма недоимки составила: по Российской Федерации — 263 044,2 млн. руб.: в т.ч. НДС - 158 601,9 млн. руб., налог на прибыль организаций - 64 116,1 млн. руб.; по Республике Дагестан 1897,3 млн. руб.: в т. ч. НДС - 1372,2 млн. руб., налог на прибыль организаций — 401,5 млн. руб. http://www. nalog.ru/
3. Оценка потенциала выделенных стратегий для конкретного предприятиядолжника.

4. Оценка затрат налогового органа на реализацию каждой выделенной стратегии.

5. Определение предельного объема недоимки, возможного к взысканию за счет использования отдельной стратегии.

6. Оценка возможности применения конкретной стратегии.

Рассмотрим подробней реализацию мероприятий из предложенного комплекса.

Проведенный анализ работы налоговых органов Росси по ликвидации налоговой задолженности позволил выделить следующие основные типовые стратегии погашения налоговой задолженности предприятий:

- реструктуризация налоговой задолженности;

- предоставление отсрочки, рассрочки и инвестиционного налогового кредита;

- задолженность, переданная налоговыми органами в Службу судебных приставов для взыскания по постановлениям о возбуждении исполнительного производства;

- урегулирование задолженности путем проведения зачета;

- изучение схем работы предприятий с коммерческими структурами, иными контрагентами, в том числе, с фирмами с сомнительной налоговой репутацией;

- у угроза применения процедур банкротства.

Отметим, что некоторые из перечисленных стратегий оказывают косвенное влияние на уменьшение налоговой задолженности и при их реализации автоматически должны быть включены другие стратегии.

Основной целью (не функцией!) деятельности налоговых органов была и 
остается мобилизация денежных средств в бюджет. Таким образом, при выборе той или иной стратегии важна такая ее характеристика, как ликвидность, то есть показатель того, насколько быстро применение данной стратегии обеспечивает погашение налоговой задолженности. Ликвидность варьирует от 0 до 1 и рассчитывается как отношение между объемом налоговой задолженности, погашаемой за счет использования каждой из перечисленных стратегий и эквивалентной ему сумме денежных средств, поступающих в бюджет. То есть, например, для стратегии, связанной с реструктуризацией, направление части выручки на погашение налоговой задолженности в объемах и рамках согласованного и утвержденного графика ликвидность будет равна 1, так как задолженность погашается полностью. Расчет коэффициента ликвидности может быть произведен в динамике для каждой стратегии при анализе данных о применении соответствующих стратегий за предыдущие периоды. Это значительно упростит процедуру выбора стратегий для применения их в будущем.

Затраты налогового органа по реализации определенной стратегии должны быть эффективными и зависят от множества факторов: ее потенциала для данного предприятия, суммы налоговой задолженности, предполагаемой к погашению за счет использования этой стратегии и т.д. Эффективность в данном случае определяется как отношение суммы средств, зачисленных в бюджет к расходам, понесенным налоговым органом на ликвидацию задолженности. При этом допускается ситуация, когда эффективная реализация одной стратегии может исключить необходимость полной или частичной реализации других стратегий, хотя реализация других стратегий будет связана с меньшими затратами.
Тогда целевая функция налогового органа по взысканию налоговой задолженности может быть определена как достижение максимальной эффективности от погашения задолженности в определенном объеме за счет реализации определенной стратегии, которая достигается тогда, когда соотношение погашенной налоговой задолженности за счет применения каждой стратегии к затратам на реализацию этой стратегии будет максимальным.

Опираясь на эти положения можно разработать оптимальный план мероприятий по снижению налоговой задолженности, для чего введем следующие переменные:

$\{i\}$-множество типовых стратегий по работе с должниками для погашения налоговой задолженности;

$N^{t}$ - объем налоговой задолженности по предприятию за период;

$V_{i}^{t}$ - средний потенциал $i$-й стратегии;

$L_{i}$ - средняя эффективность $i$-й стратегии;

$R_{i}^{t}$ - объем налоговой задолженности, погашаемой за счет применения $i$-й стратегии;

$p_{i}$ - оценка возможности применения $i$-й стратегии;

$Z^{t}$ - затраты налогового органа на реализацию $i$-й стратегии;

$$
\left\{a_{i_{j}}\right\} \text { - матрица связи затрат по реа- }
$$

лизации $i$-й стратегии и изменений затрат на реализацию $j$-й стратегии;

$\Delta N^{t}$ - разность между начисленными и уплаченными в период $t$ налогами;

$\Delta V_{i}^{t}$ - изменение потенциала $i$-й стратегии;

$\tau_{i}$ - лаг запаздывания по платежам за счет $i$-го источника; 
Решение задачи ищется на временном отрезке $\left[t_{\sigma} ;\right]$. При этом справедливы следующие предположения.

Затраты налогового органа на реализацию $i$-й стратегии определяются потенциалом этой стратегии и объемом недоимки, погашаемой за счет ее применения:

$$
Z_{i}^{t}=f\left(R_{i}^{t}, V_{i}^{t}\right)
$$

В любом указанном интервале времени должны выполняться балансы недоимки и потенциалов стратегий погашения налоговой задолженности:

$$
\begin{gathered}
N^{t}=N^{t-1}+\Delta N^{t}-\sum_{i} R_{i}^{t-\tau_{i}} p_{i} L_{i}, i \in\{i\},(9) \\
V_{i}^{t}=V_{i}^{t-1}+\Delta V_{i}^{t}-R_{i}^{t-1}-\sum_{j} a_{j i} Z_{j}^{t-1}, i, j \in\{i\} .(10)
\end{gathered}
$$

Объемы недоимки, которые могут погашаться за счет соответствующего источника, ограничены потенциалом данного источника. При этом эти объемы не могут быть отрицательными, то есть налоговый орган не производит выплат предприятиям:

$$
\begin{gathered}
R_{i}^{t} \leq V_{i}^{t},(11) \\
R_{i}^{t} \geq 0
\end{gathered}
$$

Недоимка не может быть отрицательной, то есть налоговые органы не могут изъять у предприятия средств больше, чем его задолженность. Однако это условие не всегда выполняется, например, в случаях переплаты налогов. Но учитывая, что цель предприятия заключается в минимизации налоговых платежей в бюджет, справедливо следующее ограничение:

$$
N^{t} \geq 0 \text {. }
$$

Тогда в связи с обозначенной выше целевой функцией налогового органа как достижение максимальной эффективности проводимых операций, целевую функцию деятельности налоговых органов по взы- сканию налоговой задолженности можно записать следующим образом:

$$
\frac{\sum_{t} \sum_{i} R_{i}^{t}}{\sum_{t} \sum_{i} Z_{i}^{t}} \rightarrow \max , \text { (14) }
$$

Допустим, что существует некоторая предельная сумма по каждому источнику, взыскание которой не требует от налоговых органов существенных дополнительных затрат. Другими словами, иногда у предприятий возникают недоимки таких размеров, которые они готовы оплатить сразу после получения Требования об уплате налога на основании камеральной налоговой проверки. Часто (и статистика это подтверждает) предприятия действительно готовы погасить задолженность, потому что любая выездная налоговая проверка создает дополнительные неудобства как финансовым службам, так и производственной деятельности, включая и взаимосвязи с контрагентами. Это может выразиться в виде неявных дополнительных потерь, которые несет предприятие в результате финансовых проверок. Тогда уравнение (8) можно переписать в следующей форме:

$$
Z_{i}^{t}=\left\{\begin{array}{l}
0, R_{i} \leq R_{i}^{*}, \\
f\left(R_{i}^{t}, V_{i}^{t}\right) R_{i}>R_{i}^{*},
\end{array}\right.
$$

Таким образом, решая задачу (9-15), можно определить такое множество оптимальных объемов налоговых задолженностей, взыскиваемых за счет использования $i$-й стратегии в рассматриваемом периоде, чтобы ожидаемая эффективность от принятых мер была максимальной. То есть будет сформулирована оптимальная стратегия работы налоговых органов по урегулированию и взысканию налоговой задолженности с конкретного предприятия-должника на определенный период. 


\section{Библиография:}

1. Налоговый кодекс РФ. СПС КонсультантПлюс. http://www.consultant.ru/

2. Федеральный закон от 22.12.2005 №179-Ф3. СПС КонсультантПлюс. http://www. consultant.ru/

3. Приказ ФНС России от 30 мая 2007 г. № ММ-3-06/333@ Об утверждении концепции планирования выездных налоговых проверок (в ред. Приказов ФНС России от 14.10.2008 № MM-3-2/467@, от 22.09.2010 № MMB-7-2/461@, от 08.04.2011 № MMB7-2/258@, от 10.05.2012 № MMB-7-2/297@). http://base.consultant.ru/cons/cgi/online. cgi?req=doc;base $=\mathrm{LAW} ; \mathrm{n}=129610$

4. Всемирный банк бросил тень на Россию: За время кризиса доля теневого сектора могла только подрасти // Независимая газета 23.07.2010. - http://www.ng.ru/ economics/2010-07-23/1_vb.html

5. ЗАКЛЮЧЕНИЕ Счетной палаты РФ на Отчет об исполнении бюджета Фонда социального страхования РФ за 2011 год: http://www.ach.gov.ru/userfiles/tree/katrenko12-0912-tree_files-fl-629.pdf

6. Кирина Л.С., Горохова Н.А. Сравнительная характеристика различных вариантов расчета налоговой нагрузки // Экономика. Налоги. Право. 2009. № 5. С. 56-66.

7. Кирова Е.А. Налоговая нагрузка: как ее определять? // Финансы. 2009. № 4. С. 31-34.

8. Латов Ю. В. Теневая экономика: экономический и социальный аспекты: Пробл. — темат. сб. М., 1992. - С. 92-102.

9. Литвин М.И. Налоговая нагрузка и экономические интересы предприятий // Финансы. 1998. № 5. С. 29-31.

10. Основные направления налоговой политики Российской Федерации на 2014 год и на плановый период 2015 и 2016 годов (одобрено Правительством РФ 30.05.2013 г.). СПС КонсультантПлюс. http://www.consultant.ru/

11. Официальный сайт ФНС России www. nalog.ru

12. Пансков В. Г. Налоги и налогообложение: теория и практика: учебник для бакалавриата / В. Г. Пансков. - 2-е изд., перераб. и доп. - М.: Издательство Юрайт ; ИД Юрайт, 2011. - 680 с. - Серия: Бакалавр.

13. Попов Ю.Н. Теневая экономика в системе рыночного хозяйства: учебник / Ю. Н. Попов, М. Е. Тарасов - М.: Дело, 2005. - С. 50.

14. Радаев В. Деформализация правил и уход от налогов в российской хозяйственной деятельности / В. Радаев // Вопр. экономики. - 2001. - №6. - С. 60-79.

15. Баженов А.А., Чернятьева В.Г. Методологические основы оценки бизнеса // Национальная безопасность / nota bene. - 2013. - 3. - C. 516-522. DOI: 10.7256/20738560.2013.3.7746.

16. Яворская М.В. Регулирование финансового сектора в условиях кризиса // NB: Экономика, тренды и управление. - 2013. - № 1. - C.91-110. DOI: 10.7256/23064595.2013.1.577. URL: http://e-notabene.ru/etc/article_577.html

17. В.Ю Яныгин. Вопросы устойчивого развития и будущего экономики России в XXI веке. // Тренды и управление. — 2013. — № 2. —C. 218-226. DOI: 10.7256/23079118.2013.2.8015 


\section{References:}

1. Nalogovyi kodeks RF. SPS Konsul'tantPlyus. http://www.consultant.ru/

2. Federal'nyi zakon ot 22.12.2005 №179-FZ. SPS Konsul'tantPlyus. http://www.consultant.ru/

3. Prikaz FNS Rossii ot 30 maya 2007 g. № MM-3-06/333@ Ob utverzhdenii kontseptsii planirovaniya vyezdnykh nalogovykh proverok (v red. Prikazov FNS Rossii ot 14.10.2008 № MM-3-2/467@, ot 22.09.2010 № MMV-7-2/461@, ot 08.04.2011 № MMV-7-2/258@, ot 10.05.2012 № MMV-7-2/297@). http://base.consultant.ru/cons/cgi/online.cgi?req= doc;base=LAW;n=129610

4. Vsemirnyi bank brosil ten' na Rossiyu: Za vremya krizisa dolya tenevogo sektora mogla tol'ko podrasti // Nezavisimaya gazeta 23.07.2010. - http://www.ng.ru/economics/2010-07-23/1_vb.html

5. ZAKLYuChENIE Schetnoi palaty RF na Otchet ob ispolnenii byudzheta Fonda sotsial'nogo strakhovaniya RF za 2011 god: http://www.ach.gov.ru/userfiles/tree/katrenko1209-12-tree_files-fl-629.pdf

6. Kirina L.S., Gorokhova N.A. Sravnitel'naya kharakteristika razlichnykh variantov rascheta nalogovoi nagruzki // Ekonomika. Nalogi. Pravo. 2009. № 5. S. 56-66.

7. Kirova E.A. Nalogovaya nagruzka: kak ee opredelyat'? // Finansy. 2009. №4. S. 31-34.

8. Latov Yu. V. Tenevaya ekonomika: ekonomicheskii i sotsial'nyi aspekty: Probl. - temat. sb. M., 1992. - S. 92-102.

9. Litvin M.I. Nalogovaya nagruzka i ekonomicheskie interesy predpriyatii // Finansy. 1998. № 5. S. 29-31.

10. Osnovnye napravleniya nalogovoi politiki Rossiiskoi Federatsii na 2014 god i na planovyi period 2015 i 2016 godov (odobreno Pravitel'stvom RF 30.052013 g.). SPS Konsul'tantPlyus. http://www.consultant.ru/

11. Ofitsial'nyi sait FNS Rossii www. nalog.ru

12. Panskov V. G. Nalogi i nalogooblozhenie: teoriya i praktika: uchebnik dlya bakalavriata / V. G. Panskov. - 2-e izd., pererab. i dop. - M.: Izdatel'stvo Yurait; ID Yurait, 2011. — 680 s. - Seriya: Bakalavr.

13. Popov Yu.N. Tenevaya ekonomika v sisteme rynochnogo khozyaistva: uchebnik / Yu. N. Popov, M. E. Tarasov - M.: Delo, 2005. - S. 50.

14. Radaev V. Deformalizatsiya pravil i ukhod ot nalogov $\mathrm{v}$ rossiiskoi khozyaistvennoi deyatel'nosti / V. Radaev // Vopr. ekonomiki. - 2001. — №6. — S. 60-79.

15. Bazhenov A.A., Chernyat'eva V.G. Metodologicheskie osnovy otsenki biznesa // Natsional'naya bezopasnost' / nota bene. - 2013. - 3. - C. 516-522. DOI: 10.7256/20738560.2013.3.7746.

16. Yavorskaya M.V. Regulirovanie finansovogo sektora v usloviyakh krizisa // NB: Ekonomika, trendy i upravlenie. — 2013. — № 1. — S.91-110. DOI: 10.7256/2306-4595.2013.1.577. URL: http://e-notabene.ru/etc/article_577.html

17. V.Yu Yanygin. Voprosy ustoichivogo razvitiya i budushchego ekonomiki Rossii v XXI veke. // Trendy i upravlenie. — 2013. — № 2. — C. 218-226. DOI: 10.7256/2307-9118.2013.2.8015 